\title{
Comparative Analysis of Functional Components for Tea Flower in Different Areas in Hainan
}

\author{
Chen Dongmei, Liu Xiaobing, He Jinwu, Fan Weiwei \\ Department of Education, Sanya Aviation \& Tourism College, Sanya Hainan, 572000, China \\ 11761412@qq.com
}

Keywords: Hainan, tea flower, functional components, comparative analysis

\begin{abstract}
Content of functional components, such as tea polyphenol, crude polysaccharide, total flavone, total saponins, and amino acid in tea flower and tea in main tea production area in Hainan Province, China was mainly determined in the experiment. It is found through comparative analysis that total content of tea polyphenol, tea polysaccharide, and amino acid in tea is higher than tea flower; however, content of total flavone and total saponins in tea flower is higher than that in tea. In general, functional components contained in tea flower are close to that in tea. Content of functional components of teal flower in Zhongyezhong Tea Garden on Five Finger Mountain in Hainan (organic planting) is obviously higher than that of Dayezhong tea flower in other production areas. Content of functional components respectively is: $6.5 \mathrm{mg} / 100 \mathrm{~g}$ of tea polyphenol, $1150 \mathrm{mg} / 100 \mathrm{~g}$ of crude polysaccharide, $1130 \mathrm{mg} / 100 \mathrm{~g}$ of total flavone, $761 \mathrm{mg} / 100 \mathrm{~g}$ of total saponins, and 11.01g/100g of amino acid. Content of above-mentioned components for Dayezhong tea flower in other production areas may be slightly different. Mean value of functional components for Dayezhong tea is $5.7 \mathrm{mg} / 100 \mathrm{~g}$ of tea polyphenol, $848 \mathrm{mg} / 100 \mathrm{~g}$ of crude polysaccharide, 818 $\mathrm{mg} / 100 \mathrm{~g}$ of total flavone, $507 \mathrm{mg} / 100 \mathrm{~g}$ total saponins, and $8.67 \mathrm{~g} / 100 \mathrm{~g}$ of amino acid.
\end{abstract}

In recent years, tea industry is gradually revitalized in Hainan Province where has about 20 thousand mu of planting area. Big leaf tea is universally planted in tea gardens in Hainan Province, accounting for $80 \%$ of total planting area. Planted tea varieties mainly include Hainan Dayezhong tea and Yunnan Dayezhong tea. Zhongyezhong tea is mainly in Five Finger Mountain and Chenmai and is mainly subject to organic planting. Xiaoyezhong tea tree used to be introduced. However, it has basically varied to Dayezhong tea tree due to climate in Hainan.

Dayezhong tea tree in Hainan tea garden basically blooms all the year round. The high flowering period is between July and August. Flowering season of wild Dayezhong tea is from November to February next year. Wild tea tree has small flowering amount and small flowers. Tea garden with Zhongyezhong tea tree planted in Five Finger and Chenmai in Hainan Province has the largest flowering amount and the largest output during November to February next year. $900 \mathrm{~kg} \sim 1200 \mathrm{~kg}$ of fresh flowers or flower buds can be picked up in tea garden per mu in the season with the largest output of tea flower; 1200 1500kg of fresh flowers or flower buds can be picked up in Zhongyezhong tea garden per mu. Output of Zhongyezhong tea flower is obviously higher than that of Dayezhong tea flower.

\section{Materials and instruments}

\subsection{Materials}

Experimental sample collection site: Baoting, Five Finger Mountain, Baisha, Qiongzhong, and Ding'an

Experimental sample collection of tea flower: flower bud and tea with a bud and two leaves in tea production areas

\subsection{Instruments}

722spectrophotometer: Shanghai Youke Instrument Co., Ltd.; TDL-408B centrifuge: Jintan 
Hongke Instrument Plant; UV755B ultraviolet-visible spectrophotometer: Shenzhen Dingxinyi Laboratory Equipment Co., Ltd.; WSL-2 chromometer: Shanghai Shenguang Machinery Plant; HX-1800 automatic amino acid analyzer: Wuhan Hengxin Instrument.

\section{Methods}

\subsection{Sample handling}

Fresh leaf and flower bud $\rightarrow$ sunning (sunning for $1 \mathrm{~h}$ in a sunny day) $\rightarrow$ water removing (pan-fired for $4 \mathrm{~min}$ with motorized pulley) $\rightarrow$ rolling $\rightarrow$ drying $\left(50-60^{\circ} \mathrm{C}\right.$; drying until there is $5 \%$ of moisture content) $\rightarrow$ determine samples

\subsection{Determination methods}

Tea polyphenol (calculated according to dry basis): GB/T 8313-2008 methods to determine content of tea polyphenol and catechin in tea; crude polysaccharide (calculated according to glucose): method to determine polysaccharide (anthrone colorimetry); flavone (calculated according to rutin): determination of flavone in health food; total saponins (calculated according to panaxoside $\mathrm{Re})$ : determination of total saponins in health food.

\section{Result analysis}

\subsection{Analysis of tea polyphenol}

Fig. 1 shows that content of tea polyphenol in tea is obviously higher than that in tea flower. Content of tea polyphenol in tea in different production areas ranges from $19.5 \mathrm{~g} / 100 \mathrm{~g}$ to $21.9 \mathrm{~g} / 100 \mathrm{~g}$, while content of tea polyphenol in tea flower ranges from $5.2 \mathrm{~g} / 100 \mathrm{~g}$ to $6.5 \mathrm{~g} / 100 \mathrm{~g}$. There is no obvious difference. Content of tea polyphenol in tea in organic tea garden in Five Finger Mountain is the highest, which is $21.9 \mathrm{~g} / 100 \mathrm{~g}$. Moreover, content of tea polyphenol in Zhongyezhong tea flower in organic tea garden in Five Finger Mountain is also the highest, which is $6.5 \mathrm{~g} / 100 \mathrm{~g}$.

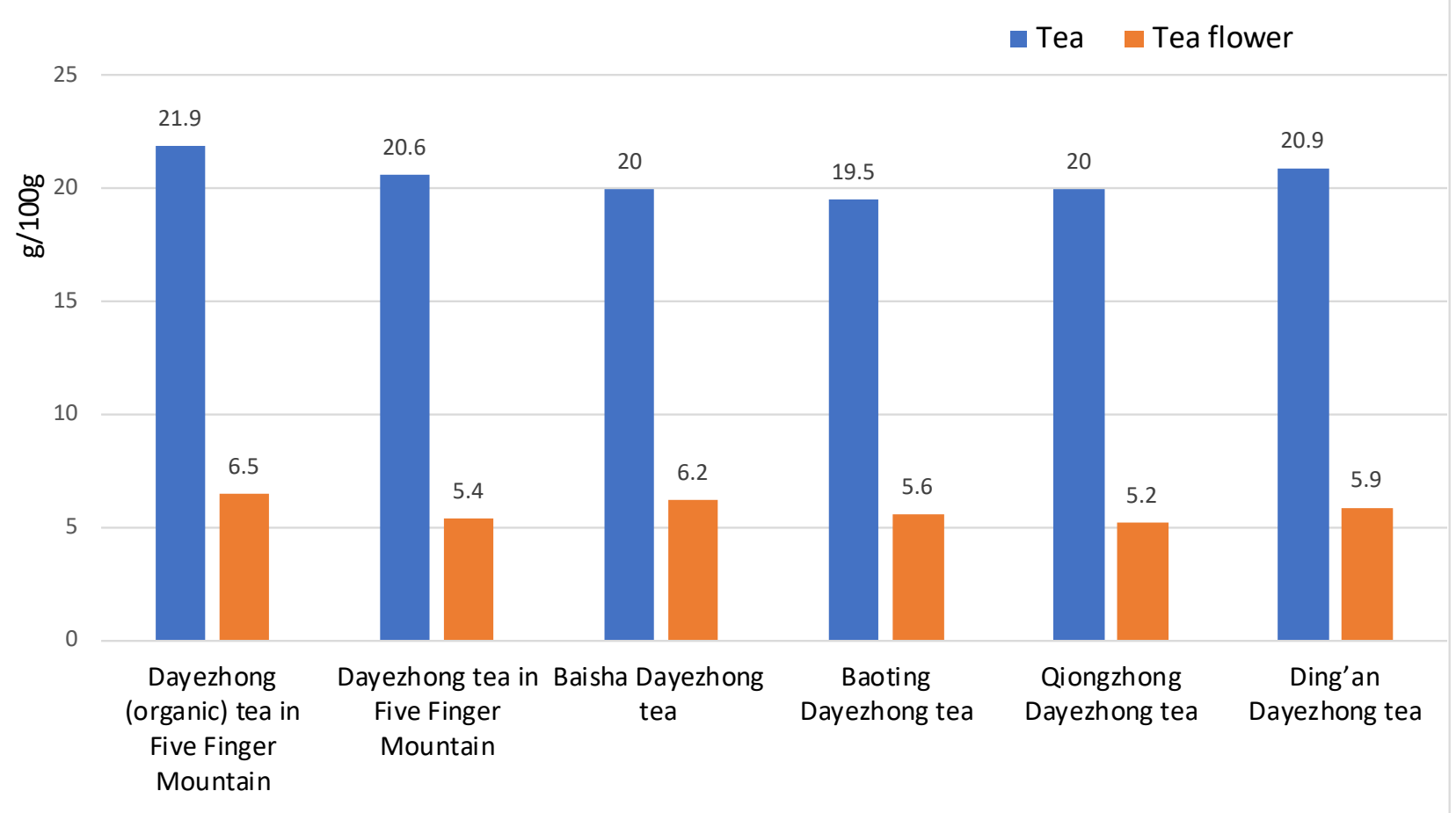

Fig. 1 Comparative Chart for Content of Tea Polyphenol in Tea and Tea Flower 


\subsection{Analysis of tea polysaccharide}

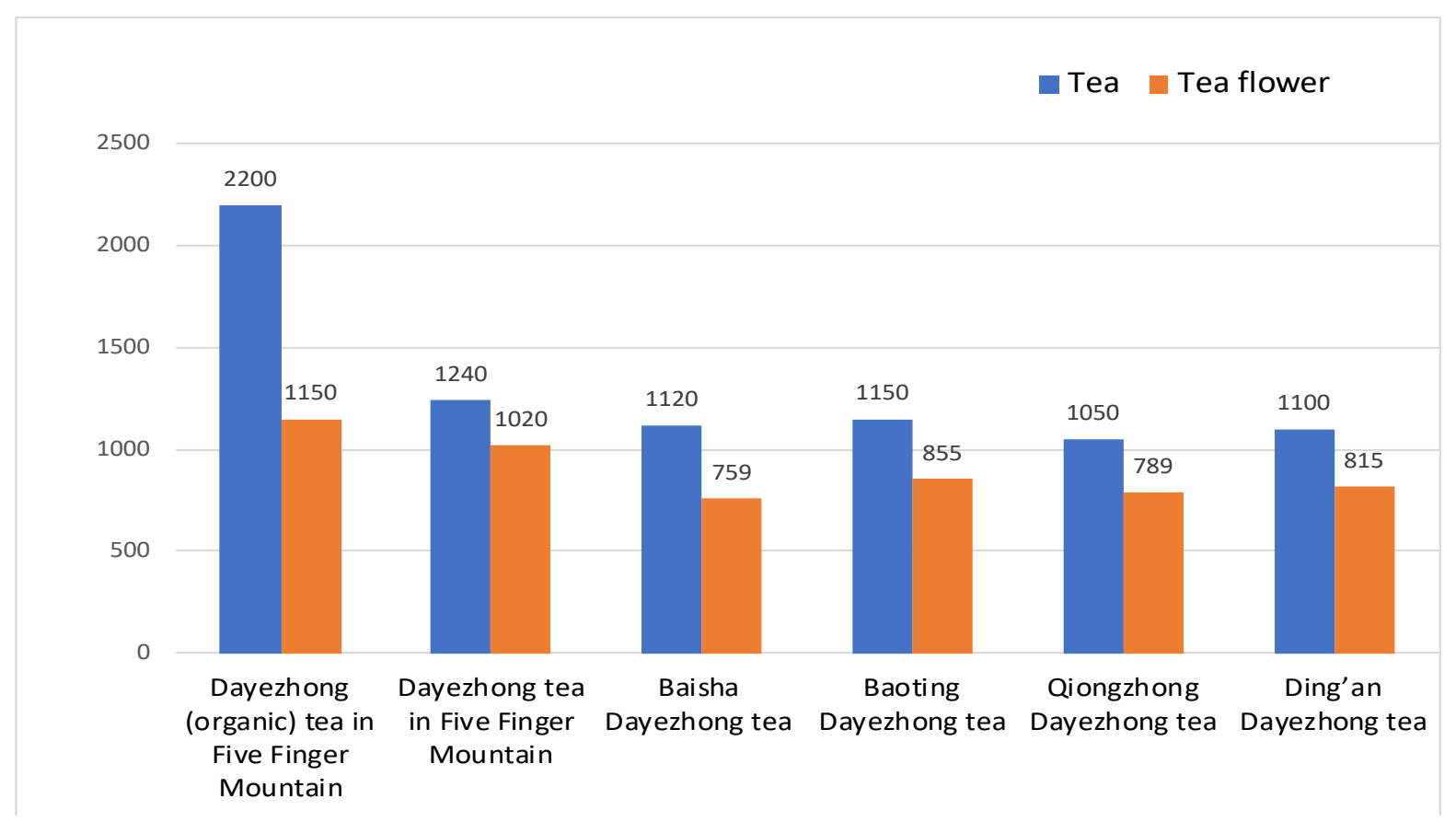

Fig. 2 Comparative Chart for Content of Crude Polysaccharide in Tea and Tea Flower

Fig. 2 shows that content of polysaccharide content in tea is higher than that in tea flower. Content of polysaccharide content in tea in different production areas ranges from $1050 \mathrm{mg} / 100 \mathrm{~g}$ to $2200 \mathrm{mg} / 100 \mathrm{~g}$, while that in tea flower ranges from $759 \mathrm{mg} / 100 \mathrm{~g}$ to $1150 \mathrm{mg} / 100 \mathrm{~g}$. Content of polysaccharide content in Zhongyezhong tea in organic tea garden in Five Finger Mountain is obviously the highest among that in tea in other production areas, which is $2200 \mathrm{mg} / 100$. There is no obvious difference in content of crude polysaccharide in Dayezhong tea in other production areas. Content of Qiongzhong Dayezhong tea is the lowest, which is $1050 \mathrm{mg} / 100 \mathrm{~g}$. Content of crude polysaccharide in Zhongyezhong tea flower in organic tea garden in Five Finger Mountain is the highest among that in tea flower in other production areas, which is $1150 \mathrm{mg} / 100 \mathrm{~g}$. Content of Baishao Zhongyezhong tea flower is the lowest, which is $759 \mathrm{mg} / 100 \mathrm{~g}$

\subsection{Analysis of total flavone}

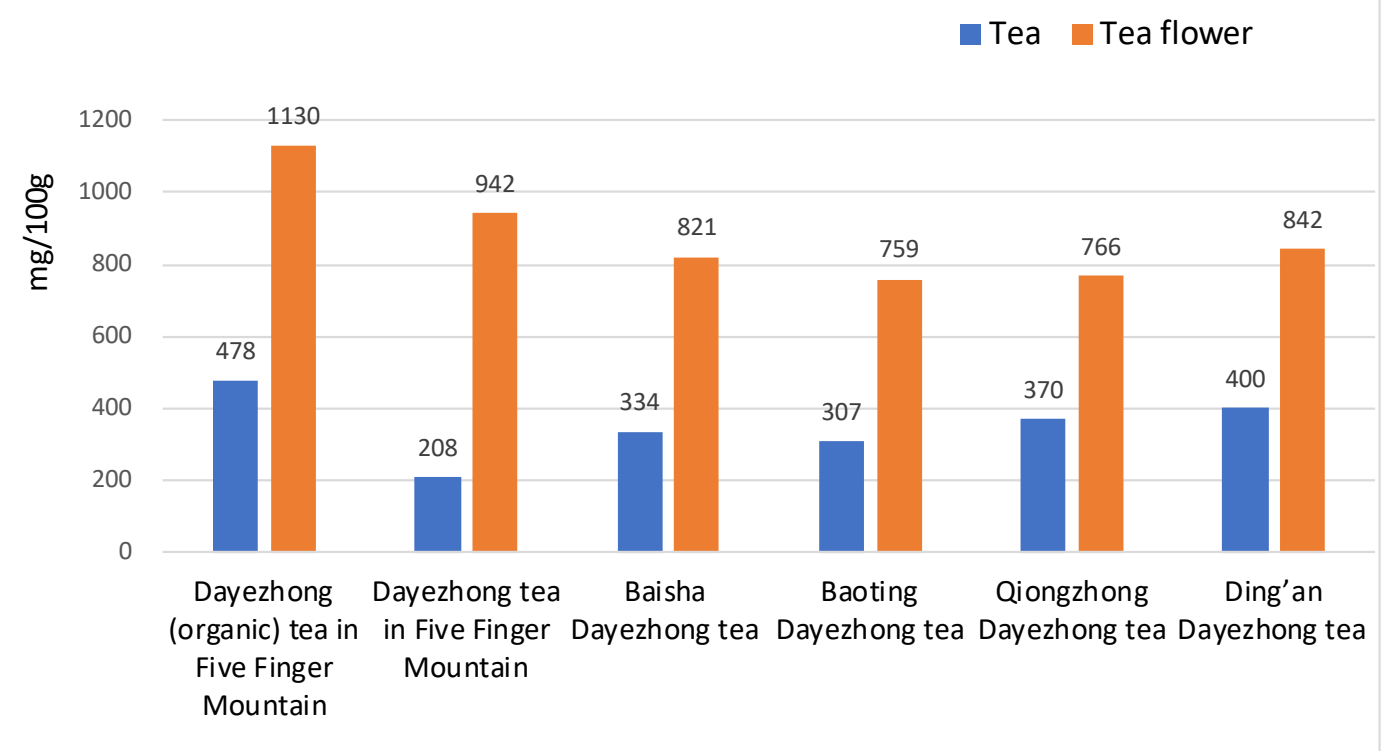

Fig. 3 Comparative Chart for Content of Total Flavone in Tea and Tea Flower 
Fig. 3 shows that content of total flavone in tea flower is obviously higher than that in tea. Content of total flavone in tea flower in different production areas ranges from $1130 \mathrm{mg} / 100 \mathrm{~g}$ to $759 \mathrm{mg} / 100 \mathrm{~g}$, while that in tea ranges from $208 \mathrm{mg} / 100 \mathrm{~g}$ to $478 \mathrm{mg} / 100 \mathrm{~g}$. Content of total flavone in tea flower and tea in organic tea garden in Five Finger Mountain is the highest amount that in other production areas, which is respectively $1130 \mathrm{mg} / 100 \mathrm{~g}$ and $478 \mathrm{mg} / 100 \mathrm{~g}$. Baoting Dayezhong tea flower and tea have the lowest content of total flavone, which is respectively $759 \mathrm{mg} / 100 \mathrm{~g}$ and $307 \mathrm{mg} / 100 \mathrm{~g}$.

\subsection{Analysis of total saponins}

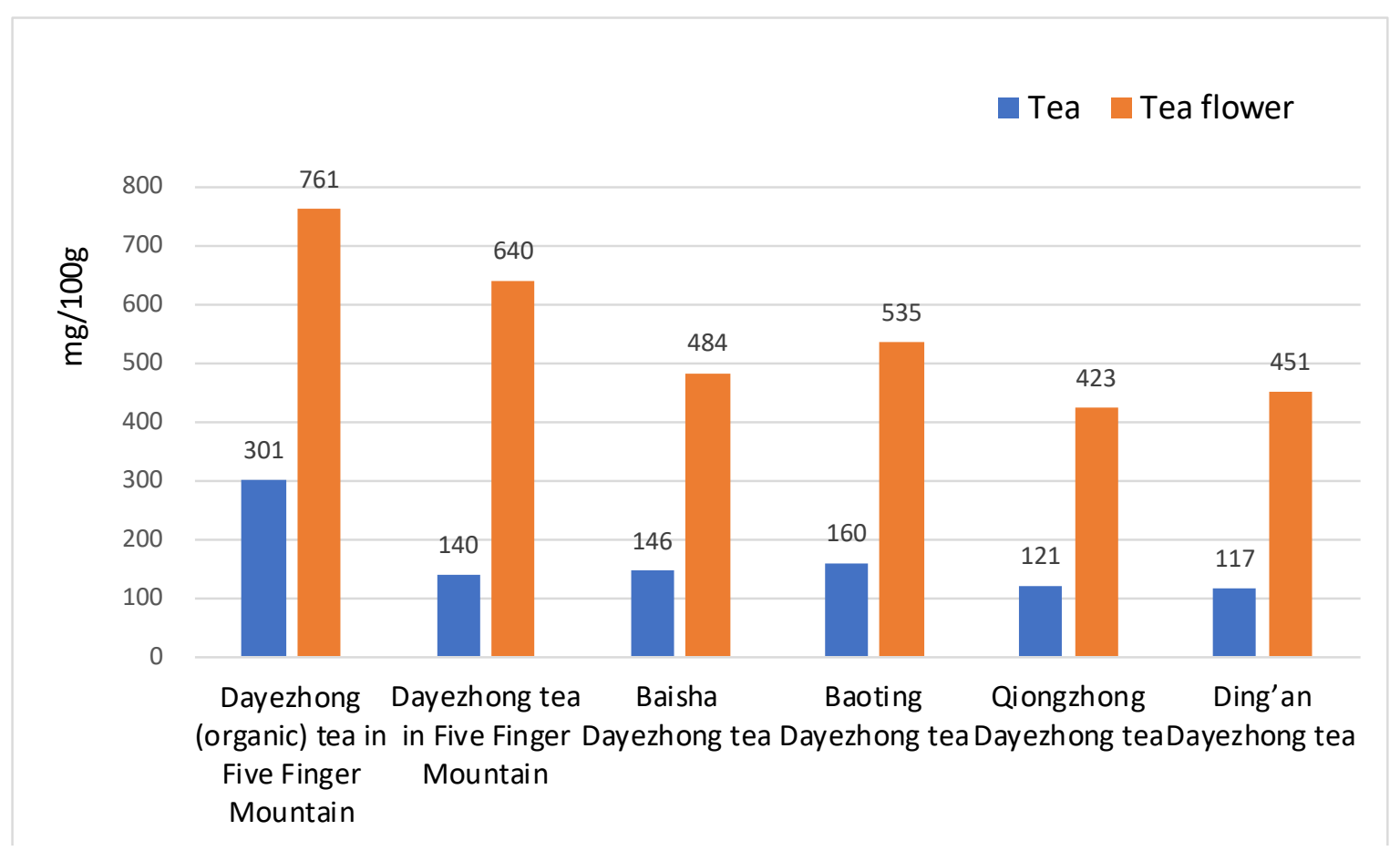

Fig. 4 Comparative Chart for Content of Total Saponins in Tea and Tea Flower

Fig. 4 shows that content of total saponins in tea flower is obviously higher than that in tea. Rank for content of total saponins in tea flower in different production areas is: Zhongyezhong in Five Finger Mountain> Dayezhong in Five Finger Mountain $>$ Baoting Dayezhong $>$ Baisha Dayezhong > Ding'an Dayezhong > Qiongzhong Dayezhong. Content of total saponins in Dayezhong tea flower and tea in organic tea garden in Five Finger Garden is the highest among that in other production areas, which is respectively 761mg/100g and $301 \mathrm{mg} / 100 \mathrm{~g}$. Qiongzhong Dayezhong tea flower and tea have the lowest content of total saponins, which is respectively 423mg/100g and 121mg/100g.

\subsection{Analysis of amino acid}

Fig. 5 shows that content of amino acid in tea is obviously higher than that in tea flower. Content of tea polyphenol in tea in different areas ranges from $22.38 \mathrm{~g} / 100 \mathrm{~g}$ to $15.82 \mathrm{~g} / 100 \mathrm{~g}$. There are obvious differences. Content of amino acid in tea flower ranges from $7.74 \mathrm{~g} / 100 \mathrm{~g}$ to $11.01 \mathrm{~g} / 100 \mathrm{~g}$. Total content of amino acid in Zhongyezhong tea in organic tea garden in Five Finger Mountain is the highest, which is $22.38 \mathrm{~g} / 100 \mathrm{~g}$. Content of amino acid in Zhongyezhong tea flower in organic tea garden in Five Finger Garden is the highest among that in other tea flower, which is $11.01 \mathrm{~g} / 100 \mathrm{~g}$. Content of amino acid in Baisha Dayezhong tea is the lowest among that in tea, which is $15.82 \mathrm{~g} / 100 \mathrm{~g}$. Content of amino acid in Baisha Dayezhong tea flower is the lowest among that in other tea flowers, which is $7.74 \mathrm{mg} / 100 \mathrm{~g}$. 


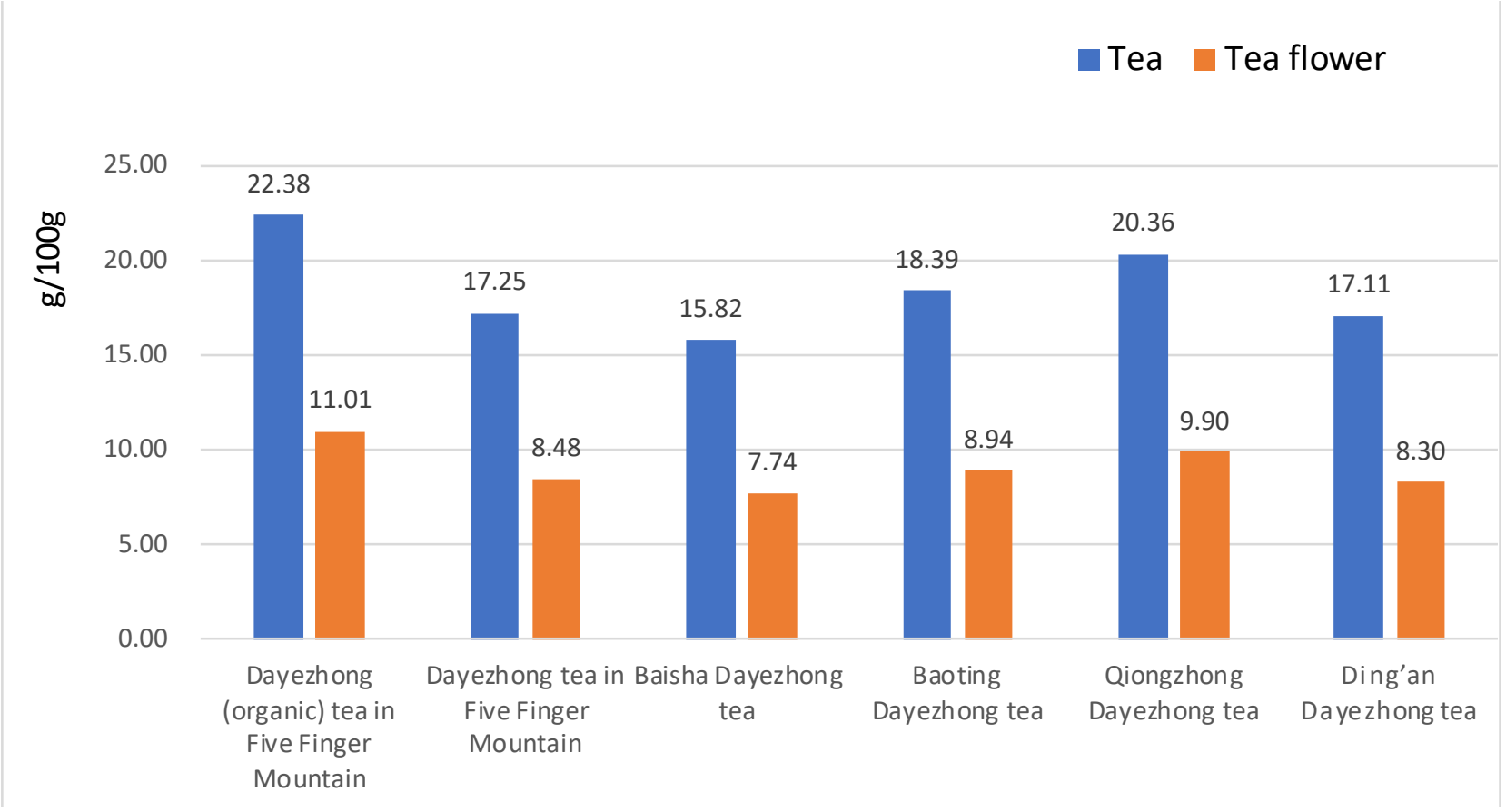

Fig. 5 Comparative Chart for Total Content of Amino Acid in Tea and Tea Flower

3.6 Analysis of functional components in tea flower

Table 3 Table for Main Functional Components of Tea Flower

\begin{tabular}{|c|c|c|c|c|c|c|c|}
\hline $\begin{array}{c}\text { Functional } \\
\text { components }\end{array}$ & $\begin{array}{c}\text { Organic } \\
\text { Zhongyezhong }\end{array}$ & $\begin{array}{c}\text { Dayezhong } \\
\text { in Five } \\
\text { Finger } \\
\text { Mountain }\end{array}$ & $\begin{array}{c}\text { Ding'an } \\
\text { Daye }\end{array}$ & $\begin{array}{c}\text { Baisha } \\
\text { Daye }\end{array}$ & $\begin{array}{c}\text { Qiongzhong } \\
\text { Daye }\end{array}$ & $\begin{array}{c}\text { Baoting } \\
\text { Daye }\end{array}$ & $\begin{array}{c}\text { Mean } \\
\text { value of } \\
\text { Daye }\end{array}$ \\
\hline Tea polyphenol & 6.5 & 5.4 & 6.2 & 5.6 & 5.2 & 5.9 & 5.7 \\
\hline $\begin{array}{c}\text { Crude } \\
\text { polysaccharide }\end{array}$ & 1150 & 1020 & 759 & 855 & 789 & 815 & 848 \\
\hline Total flavone & 1130 & 902 & 821 & 759 & 766 & 842 & 818 \\
\hline Total saponins & 761 & 640 & 484 & 535 & 423 & 451 & 507 \\
\hline Amino acid & 11.1 & 8.48 & 8.30 & 7.74 & 8.94 & 9.90 & 8.67 \\
\hline
\end{tabular}

Fig. 3 shows that functional components of tea flower in (organic planted) Zhongyezhong tea garden in Five Finger Mountain in Hainan Province is obviously higher than that of Dayezhong tea flower in other production areas. Content of functional components is respectively: $6.5 \mathrm{mg} / 100 \mathrm{~g}$ of tea polyphenol, $1150 \mathrm{mg} / 100 \mathrm{~g}$ of crude polysaccharide, $1130 \mathrm{mg} / 100 \mathrm{~g}$ of total flavone, $761 \mathrm{mg} / 100 \mathrm{~g}$ of total saponins, and $11.01 \mathrm{~g} / 100 \mathrm{~g}$ of amino acid. Content of above-mentioned functional components for Dayezhong tea flower in other production areas may be slightly different. Mean value of functional components for Dayezhong tea is $5.7 \mathrm{mg} / 100 \mathrm{~g}$ of tea polyphenol, $848 \mathrm{mg} / 100 \mathrm{~g}$ of crude polysaccharide, $818 \mathrm{mg} / 100 \mathrm{~g}$ of total flavone, $507 \mathrm{mg} / 100 \mathrm{~g}$ of total saponins, and $8.67 \mathrm{~g} / 100 \mathrm{~g}$ of amino acid.

\section{Conclusion}

Based on above-mentioned analysis, functional components of tea flower in (organic planted) Dayezhong tea garden in Five Finger Mountain in Hainan Province is obviously higher than that in Dayezhong tea flower in other production areas. Content of functional components is respectively: $6.5 \mathrm{mg} / 100 \mathrm{~g}$ of tea polyphenol, $1150 \mathrm{mg} / 100 \mathrm{~g}$ of crude polysaccharide, $1130 \mathrm{mg} / 100 \mathrm{~g}$ of total flavone, $761 \mathrm{mg} / 100 \mathrm{~g}$ of total saponins, and $11.01 \mathrm{~g} / 100 \mathrm{~g}$ of amino acid. Content of above-mentioned functional components for Dayezhong tea flower in other production areas is slight different. Mean value of functional components for Dayezhong tea is $5.7 \mathrm{mg} / 100 \mathrm{~g}$ of tea 
polyphenol, $848 \mathrm{mg} / 100 \mathrm{~g}$ of crude polysaccharide, $818 \mathrm{mg} / 100 \mathrm{~g}$ of total flavone, $507 \mathrm{mg} / 100 \mathrm{~g}$ of total saponins, and $8.67 \mathrm{~g} / 100 \mathrm{~g}$ of amino acid.

It is found through comparative analysis of functional components for Dayezhong tea and tea flower that total content of tea polyphenol, tea polysaccharide, and amino acid in tea is higher than that in tea flower. However, content of total flavone and total saponins in tea flower is higher than that in tea. In general, functional components contained in tea flower are similar to that contained in tea. Moreover, amino acid composition is similar to each other.

\section{Acknowledgement}

Fund projects: Hainan University Scientific Research Funding Project

The Research status and Adaptation Analysis of Wild Tea in Wuzhishan (No. Hnky2018-98)

\section{References}

[1] Diao Mengyao, She Lin, and Sheng Jiping. Current situation and outlook of research utilization of tea flower resources [J]. Food and Nutrition in China, 2017, 23 (12):24-28.

[2] Huang Xiao, Wang Bingwu, et al. Influences of different drying methods on quality of tea flower [3]. Food Science and Technology, 2017, 42 (12): 82-87.

[3] Chen Dongmei, He Jinwu, and Fan Weiwei. Analysis of flowing for different varieties of tea trees in Hainan Province and functional components for tea flower [J]. Farm Products Processing, 2018(04):52-53+57.

[4] Chen Dongmei, Li Ming,and Chen Mingxing. Analysis of functional components for tea flower in Five Finger Mountain [J]. Food Research and Development, 2017, 38 (07): 119-121.

[5] Wang Yaguang. Determination methods of functional components for health food [M]. Beijing: China Light Industry Press, 2002: 15

[6] Ministry of Health of the PRC. Technical specification of detection and evaluation for health food (WFJF [2004] 42) [Z]. 2003, 02, 14 